\title{
The Effects of a Cognitive Apprenticeship Model on the Argumentative Texts of EFL Learners
}

\author{
Ioanna K. Tsiriotakis ${ }^{1}$, Valia Spiliotopoulos ${ }^{2}$, Matthias Grünke ${ }^{3}$ \& Costas Kokolakis ${ }^{4}$ \\ ${ }^{1}$ Faculty of Education, University of British Columbia, Vancouver, British Columbia, Canada \\ ${ }^{2}$ Department of Language \& Literacy Education, Faculty of Education, University of British Columbia, Canada \\ ${ }^{3}$ Department of Special Education \& Rehabilitation, School of Human Sciences, University of Cologne, Germany \\ ${ }^{4}$ Mineral Resources Engineering Department, Technical University of Crete, Greece \\ Correspondence: Ioanna K. Tsiriotakis, Department of Primary Education, School of Education, University of \\ Crete, 800-15355 24 ${ }^{\text {th }}$ Ave. Suite 635 Surrey, BC V4A 2H9, Canada. E-mail: ioannatsiriotakis@gmail.com
}

\author{
Received: July 5, $2021 \quad$ Accepted: August 7, $2021 \quad$ Online Published: August 11, 2021 \\ doi:10.5539/jel.v10n5p63 URL: https://doi.org/10.5539/jel.v10n5p63
}

\begin{abstract}
In the present study, a quasi-experimental pre-post test design was used to assess the effects of an argumentative writing strategy (POW+TREE) on the performance of grade five and six students of Greek origin who were learning English as a foreign language (EFL) in a Greek setting. The Self-Regulated Strategy Development (SRSD) cognitive apprenticeship model was utilized to improve the text composition skills of the students. In the experimental group $(\mathrm{N}=77)$, participants received instruction on general and genre-specific strategy use for planning and writing argumentative essays, on procedures to apply self-regulation (goal setting, self-monitoring, self- reinforcement, and self-instructions), and on establishing additional skills (vocabulary, grammar-drill instruction, good word choice, interesting openings etc.). The control group $(\mathrm{N}=100)$ was supported through a traditional curriculum in writing (focusing on spelling and grammar). Findings of the study showed that strategy instructed students wrote argumentative essays that were schematically stronger, qualitatively better, and longer than those produced by their counterparts in the control group.
\end{abstract}

Keywords: SRSD, EFL explicit writing instruction, cognitive apprenticeship, self-regulation

\section{Introduction}

\subsection{The Significance of Writing Argumentative Essays in English as a Foreign Language}

One of the main goals of education is to teach students to think critically. A key-way to do that is to help them write argumentative essays. These kinds of texts are defined by strong, well-researched argumentation. They attempt to convince the readers to agree with the writer on an issue in question. Argumentative texts require authors in an exceptional manner to choose their words carefully and to reason logically. Thus, composing them is often considered the most demanding of all writing activities (Weigle, 2002). It is important for young students to develop effective argumentative writing skills from an early age as they are imperative to academic writing and future work (Kellogg \& Raulerson, 2007).

For the purpose of this paper L1 refers to students whose native language is Greek and L2 refers to students of Greek origin, learning English as a foreign language in a Greek setting. Learning to produce argumentative essays in one's native language is sufficiently challenging; learning how to compose them in a foreign language is considerably more difficult. This is particularly striking for students with writing difficulties. While they struggle to learn how to compose in their native language, their difficulties are magnified when attempting to learn how to compose in a foreign tongue (Manchón \& Matsuda, 2016). English has become the world's primary language due to globalization and migration (Burbules \& Torres, 2000; Graddol, 2006). It is used as a lingua franca for international communication, business, education, science, and industry (Melitz, 2018). Furthermore, it is the principal language of educational instruction in many countries (Dearden, 2015; Graddol, 2006). The Greek Educational system has hence chosen English as the primary foreign language to be taught in primary schools due to its global status and rapid growth in educational settings (Dearden, 2015).

A good command of English as a foreign language (EFL) is a vital instrument for school success but also for life 
opportunities such as the prospect of studying or working abroad as well as economic and personal growth (Graham \& Harris, 2014). Failing to acquire an adequate EFL writing proficiency level would place students with writing difficulties in a severely disadvantaged position and may potentially exclude them from both academic and economic opportunities. Individuals who are capable of producing all different kinds of text genres (ranging from simple narratives to sophisticated essays geared towards persuading readers of a particular point of view) are certainly in a favorable situation in higher education and in the job market. Not only because a lot of academic and occupational tasks require adequate writing abilities, but also because text production skills go hand in hand with reasonable reflective thinking that is aimed at solving complex problems. Thus, it is vital to efficiently support students at risk for failure so that they too, have the opportunity to lead a fulfilling life (Martinez Agudo, 2014). Although this study is exclusively based on students whose L1 is Greek, it should be noted that learning English as an L2 is the preferred choice of most countries where English is not the L1 (Graddol, 2006).

\subsection{Writing Difficulties in the L1 and L2}

Writing is a challenging task for all students (Graham \& Harris, 2000). However, empirical research has validated that it is even more challenging for students with writing difficulties (Graham et al., 2017; Graham, Harris, \& McKeown, 2013). They face a plethora of composing challenges that impede their ability to produce texts of adequate quality. Students with writing difficulties compose essays that are less polished, expansive, coherent, and effective (Harris \& Graham 1999) compared to their typically achieving peers. They also face challenges with low-level transcription skills (handwriting and spelling) (Graham \& Harris, 2000). In addition, these students are not able to adhere to the rules and principles of punctuation and grammar, to organize their thoughts well enough to take meaningful notes, to manage their ideas in a coherent manner and to choose appropriate words (Harris, Graham, \& Mason, 2003). They demonstrate a lack of self-regulation skills for planning, evaluating, monitoring, drafting, revising, and managing the writing process (Graham et al., 2018). Additionally, they overemphasize the role of mechanics in writing, overestimate their writing abilities and engage in knowledge telling (Bereiter \& Scardamalia, 1987). Students with writing difficulties do not sufficiently use effective strategies to successfully complete a writing task at hand (Santangelo, Harris, \& Graham, 2008). Their lack of self-regulated behaviour for planning interferes with the organization of the text and goal setting (Harris et al., 2002).

Learning to write in an L2 is a highly complex process (Kroll, 2003) and develops with a great deal of variation amongst students (Samway, 2006). Nonetheless, such a task is even more difficult for students with writing difficulties. Based on studies conducted on text production within the cognitive framework, the composing processes of skillful or above average writers requires a high level of self-regulation and metacognitive control (Bereiter \& Scardamalia, 1987; Flower \& Hayes, 1980; Kellogg, 1996). Hence, young learners who have not yet mastered their L1 composition skills will face even greater difficulty composing in an L2.

\subsection{Cognitive Processes in Writing}

Writing in an L2 requires the availability of L2 linguistic knowledge and the automatic application of it. The developing nature of linguistic and metacognitive knowledge as well as fluency or accessibility to it make foreign language writing a difficult skill to acquire (Ruan, 2005). According to Cummins' theory of 'Cognitive Academic Language Proficiency', the linguistic demands of the academic context add to the 'cognitive load' (Cummins, 2008), particularly in the intermediate or secondary school contexts where literacy practices are honed. These demands create an "extra burden that overwhelms the limited capacity of short-term memory" (Flower \& Hayes, 1981, p. 373) and justifies the differences found between expert and inexpert writing processes and products. Putting thoughts on paper requires higher level cognitive processing and highly complex metacognitive skills (Cummins, 2008; Englert \& Mariage, 2003; Harris, Graham, Mason, \& Saddler, 2002; Kellogg, 1996). Self-regulated writers set goals, plan, and manage the writing process. They also evaluate their achievements and learning progress. In antithesis, students with writing difficulties not only struggle with low-level skills (handwriting, spelling, developing syntax), but also with high-level skills (conscious decision making and goal setting) (Wong, 1998). It is highly significant therefore that students with writing difficulties and specifically those acquiring an L2 are supported through interventions that focus on developing writing strategies for self-regulation and control of the writing process.

\subsection{Cognitive Strategy Writing Instruction}

Current meta-analyses identify the Self-Regulated Strategy Development (SRSD) model as the most effective cognitive framework to teach writing (e.g., Datchuk \& Kubina, 2015; Gillespie \& Graham, 2014; Gillespie, Rouse \& Sandoval, 2018; Rogers \& Graham, 2008). It was designed by Harris and Graham (1999) and is based on multiple theories and research bases. Over 100 studies have determined SRSD as an evidence-based practice. This means that it is built on the best evidence from well-designed studies. Specifically, experimental randomized 
studies conducted worldwide have shown that students greatly benefit when teachers use SRSD writing instruction in their classroom. Explicit instruction is one of the evidence-based practices that SRSD includes (Rogers, Hodge, \& Counts, 2020). SRSD breaks the teaching process into six distinct parts: (a) determine the skills needed to acquire a given strategy and assess whether students possess them, (b) introduce the particular strategy (c) demonstrate how it is applied, (d) help students memorize the strategy's steps, (e) scaffold them through the process, and (f) monitor students while they try using the strategy independently.

Within the SRSD framework, different writing strategies can be imparted. For Mason (2013), the prime approach for teaching argumentative essay skills is a combination of the techniques "POW" (an acronym for "pick an idea", "organize notes", and "write and say more") and "TREE" (an acronym for "topic sentence", "reasons", "explain reasons", and "ending"). POW was developed to aid the students' text planning by guiding them through the process of stating an opinion (pick an idea), using TREE to structure one's writing (organize notes) and composing a paragraph by following the plan developed applying the TREE strategy (write and say more). TREE was designed to help students produce solid argumentative essays by reminding them to tell what they believe (topic sentence), provide three or more points to support their position (reasons), justify their rationale (explain reasons), and create a convincing conclusion (ending; Shora \& Hott, 2016).

The application of POW+TREE within an SRSD framework has repeatedly proven to be very effective with students throughout elementary and middle school (Benedek-Wood, Mason, Wood, Hoffman, \& MacGuire, 2014; Ciullo, Mason, \& Judd, 2021; Mason, Kubina, Kostewicz, Cramer, \& Datchuk, 2013; Miller \& Little, 2018) as well as throughout high school (Hoover, Kubina, \& Mason, 2012). However, no studies exist to date testing the benefits of the approach with EFL grade school students. What is more, limited research to date addresses L2 writing for students with writing difficulties. Hence, it is fundamental that these learners are supported so that their difficulties do not become a barrier to their academic progress. Moreover, the benefits of POW+TREE will be helpful to educators who teach English as a second language as it explicitly teaches students to use the planning, drafting, and revising strategies used by skillful or above average writers.

\subsection{Purpose of the Study}

To the best of our knowledge, no studies to date have investigated the effects of teaching POW+TREE within an SRSD framework to grade school students acquiring English as L2. Thus, the purpose of the current research was to examine the benefits of POW+TREE on EFL fifth and sixth graders' written products. Moreover, this study targeted the question of the use of this approach to students who struggle with writing.

\section{Method}

\subsection{Participants and Setting}

The sample of this investigation consisted of one-hundred and seventy-seven students who voluntarily participated. Their ages ranged from eleven to twelve years. All of them were of Greek background and were randomly drawn from two mainstream primary schools in the city of Chania, Crete. One school was located north of the city and the other on the west side. Ninety students were enrolled in grade five and eighty-seven students were enrolled in grade six.

Each participating school had two grade-five and two grade-six groups that is, a total of eight groups. Classroom sizes ranged between twenty to twenty-five students. The ethics committee from the school district of Chania allowed the researcher to access various elementary schools in the area. A standard informed consent process took place prior to the data collection. Students were advised about the process and that their responses will be confidential and only used for the purpose of this investigation. Primary school students in Greece attend three 45-minute English sessions per week. A compulsory course book (student's book and teacher's book) written by The Greek Pedagogical Institute outlines the progression of each lesson. Every session includes practice in all four language skills that is, writing, listening, reading, and speaking.

The classroom teachers confirmed that the students rarely engaged in writing tasks. They also stated that they did not instruct them in writing strategies such as planning or revising. The traditional curriculum included grammar and vocabulary drill practice, through fill-in the gap exercises with minimal engagement in writing tasks.

\subsection{Design}

In order to examine the effects of the intervention, a mixed methods research design was used with a quasi-experimental pre-test and post-test research (Cook \& Campbell, 1979). This design was used because a better understanding is obtained when amalgamating quantitative methods in a research study; a factor that leads to more valid conclusions. A quasi-experimental design was applied because completely random assignments of subjects to different treatment conditions is difficult or even impossible in the school environment as in many other 
cases. Although such a research plan is not as robust and reliable as randomized controlled trials, it is the only one applicable in real life conditions like those of a school (Thyer, 2012). The students from a school in the north of Chania served as the experimental group and those from the west as the control group.

\subsection{Instruments}

A free writing task was used to assess the students' text production abilities at pre-test and post-test. They were asked to compose an argumentative paper on the topic "Should children be allowed to choose their own pets?" or write on a respective essay on a topic of their choice. Students from both groups were informed that there were no time constraints for them to finish their writing assignment. They were also told that assistance would not be provided to them apart from spelling.

All pre-test and post-test papers were scored by two graduate university students blind to the scope of the study. The first author had trained both raters so as to ensure that they were able to assess all measures of the argumentative text. Training ended when $95 \%$ of agreement was reached. The two raters' average outcome was the score for students' papers. Papers were appraised following the completion of the study. Surface level features were disregarded so as to concentrate on the quality of the writing (Graham, 1999).

Argumentative papers were scored for analytic criteria that included organization, cohesion, expansion of ideas, aptness of word choice, originality, expression (sentence variety), coherence (linking words), grammar, and syntax (a copy of the scoring sheet can be obtained from the first author upon request). Texts were also scored based on the total number of words written. Total number of words included all written words that represented a recognisable word regardless of spelling. A traditional holistic rating scale by Cooper (1997) was used to appraise the compositional quality. To assist the raters with scoring an anchor paper (with a high, middle and low-quality score) was provided. The graduate university students initially read each argumentative paper to assess its quality and then evaluated them based on a Likert-type scale with 1 representing the lowest quality of writing and 8 the highest (a copy of the rubric can be obtained from the first author upon request).

To evaluate students' writing proficiency level students' pre-test and post-test writing samples were used. Once the raters scored the papers, they then divided them into two categories: below average and average. This factor enabled us to evaluate the effects of the intervention on students with different writing skills. Those learners who fell below the mean score were considered students with writing difficulties.

\subsection{Procedures}

After the pre-test and post-test was administered (see above), the subjects in both groups attended three 45 -minute English language sessions per week, for 15 consecutive weeks. The experimental group received explicit strategy-based instruction through the SRSD writing model (Harris and Graham 1996), whereas the control group received traditional instruction (the lesson plan can be obtained upon request from the first author). Training for both groups took place in their regular classrooms. Specifically, following these procedures the experimental group students would be able to:

Students Would Be Able To (SWBAT):

(a) Experimental Group SWBAT:

Generate ideas and include basic genre-specific elements. Choose a topic, consider purpose, identify the audience, gather their ideas, and organize their ideas.

(b) Experimental Group SWBAT:

Apply self-regulation procedures that is, goal setting, self-monitoring, self-reinforcement, and self-instructions.

(c) Experimental Group SWBAT:

Utilize procedural facilitative procedures, that is, special supportive tools that would assist them throughout the process and ensure that the writing objective is being met. Procedural facilitation tools included mnemonic charts, flashcards, graphic organizers, transition words, million-dollar words (powerful, descriptive, or convincing words), transfer-sheets, self-statements (positive self-talk statements or phrases), the use of technology, and role-play.

The control group followed the traditional English program that is based on course books written by the Greek Pedagogical Institute (Efremidou, Reppa, \& Frouzaki, 2009; Efremidou, Frouzaki, \& Reppa, 2009; Kolovou \& Kraniotou, 2009; Kolovou \& Kraniotou, 2009).

The practitioner-researcher (first author) taught all eight classrooms for both the control and the experimental groups. A lesson plan was used with detailed instructions of what to implement in each lesson (Tsiriotakis, 2013, pp. 204-219) and a checklist to tick off each completed step (Harris, Graham, Mason, \& Friedlander, 2008, p. 159). 
Students were given a six-page lesson plan with detailed instructions for each step and the POW+TREE mnemonics in large colorful print (available from the first author). Assistance and clarification about instructions was provided to the students upon request throughout the process. Greek was used as a foundation to produce the English language. Throughout all 6 stages of the SRSD strategy the practitioner-researcher significantly emphasised the development of students' speaking, listening, and pronunciation skills. The evolution of oral communication skills (speaking, listening, and the subset of both speaking and listening, that is, pronunciation) are indispensable elements of an effective ESL curriculum design. Speaking and listening skills are reciprocal and interdependent oral language processes. A thorough depiction of the process can be provided by the first author upon request (see Tsiriotakis, 2013, pp. 180-184).

Stages 1 and 2 of the SRSD—Develop and Activate Background Knowledge; Discuss it

In sessions 1-5 the practitioner-researcher firstly built enthusiasm for the genre (promoted the genre). Students were told that they were going to learn a "trick" that good writers use to write good argumentative essays. Then, the practitioner-researcher read and discussed exemplary opinion essay models to assess students' background knowledge, vocabulary, and genre knowledge and subsequently, introduced the POW+TREE strategy mnemonic. The practitioner-researcher and the students then read and discussed argumentative essays so that students could develop declarative, procedural, and conditional knowledge (e.g., "What is a point of view", "How many parts does an argumentative essay have", "What parts does an argumentative essay have", "Why is x part necessary?", "Does this argumentative model have all its parts?", "Is this reason convincing", "What did the author do when he/she got discouraged?") (Hacker et al., 2009). Students' knowledge about the genre was developed up until stage 4 of SRSD. Next, the practitioner-researcher introduced the mnemonics for POW and TREE and began teaching the strategy. The graphic organizers were displayed on power point and provided as a handout. Exemplary and non-exemplary models for mapping on graphic organizers were used to help students identify if all three reasons were included and if the reasons made sense. The practitioner-researcher discussed and explored writing and self-regulation strategies, self-talk, goal setting statements and self-monitoring, as well as generalization (applying the strategy to other genres such as reports etc.). She modeled taking notes on the graphic organizer. Then, the practitioner-researcher focused on students' mastery of skills and methodically examined progress. First, she helped the students graph their own progress, develop their own self-talk and goal-setting statements. Students worked collaboratively in groups of two or three and practiced recalling, explaining, and translating the steps of the SRSD/techniques. Students repeated this process up until the final lesson (step 6 of the SRSD). To assist students in this step, procedural facilitation tools were included through the use of flash cards, colourful markers, scratch paper, power-point displaying the steps of the POW+TREE mnemonics, and role play. Students mapped multiple models using graphic organizers. They identified good argumentative writing elements in models, but also practiced improving poor models. Students also pinpointed whether all or part of the TREE elements were present, and then made adjustments. Finally, the concept of transfer was promoted. In collaborative partnerships, students discussed whether all, or parts of, the POW+TREE strategy could be applied to another writing genre (narratives, letters, school newspaper articles, ...).

At this stage, the practitioner-researcher facilitated students to graph their own progress, produce their own self-talk, and goal-setting statements, and generalize applying the strategy to other settings, and areas of study. Then, students began recalling, explaining, and translating the steps of the SRSD model through the help of procedural facilitative tools (flash cards, colorful markers, scratch paper, power-point displaying the steps of the POW+TREE mnemonics, role play, and mini quizzes in groups of two).

\section{Stage 3 of the SRSD-Model It}

In sessions 5-10 the practitioner-researcher implemented think-aloud techniques and used the "I do", "We do", "You do" model. Firstly, she modelled planning and writing an argumentative paper using a graphic organizer, then scored the essay using a rubric, and finally set goals based on the results. The practitioner-researcher thought aloud while planning and writing the essay and used self-statements. Then, she used collaborative modelling and guided students to steadily establish their own self-instructions and develop and record their own self-statements and gradually accountability was released to them. A rainbow chart was used to colour the parts of the essay. Instruction was tailored to students' needs. A reward champion card was given to students once they found all the parts of TREE.

To boost instruction and make learning meaningful, role play was introduced as well as the concept of a debate. This activity assisted students revise the TREE parts and practice communicating in real every-day situations. Students worked collaboratively and prepared a debate presenting their point of view, so as to convince their audience on a given topic. They began by re-examining the five parts of a given essay prompt. They refined the 
three reasons, engaged in debate rehearsal, and presented their debate to the whole class.

\section{Stage 4 of the SRSD-Memorize It}

In sessions 11-15 the practitioner-researcher concentrated on having students work in groups to revise the steps of POW+TREE, as well as its translation and continued practice until students had memorized the strategy mnemonic and its steps. The same process took place so as to have students practice improving, and essentially internalizing their self-instructions and self-statements. To reinforce instruction, the weaker students were placed in the same group as the stronger students. Procedural facilitation included the use of the TREE reminder chart, graphic organizers, word lists (i.e., linking words, effective vocabulary) and a self-statements list. The practitioner-researcher and the students set an aim to include all five parts in the essay, re-examined their goals, and then, collaboratively planned and wrote an essay. Most of this process was now directed by the students while the instructor served as a facilitator.

\section{Stage 5 of the SRSD - Support It}

In sessions 16-20 the practitioner-researcher focused on the gradual release of responsibility (ex. prompts and guidance) to the students. At first, the practitioner-researcher and the students collaboratively used writing, and self-regulation activities and practiced composing an essay. The POW+TREE strategy charts were provided as a handout but were also on power-point display so as to assist struggling learners. Students collaboratively practiced writing an essay using their personal self-statement sheets and goals as well as their world list and graphic organizers. Most students at this stage had replaced their graphic organizers with notes on scratch paper. However, some of them still had difficulty recalling the mnemonic parts. The practitioner-researcher provided individualized support and grouped them with classmates who had mastered stage 5 of the SRSD to assist them. Procedural facilitation in these sessions (stage 5 of the SRSD) included the same activities as in the previous stages.

Stage 6 of the SRSD - Establish Independent Performance

During sessions 20-25, being the last stage of the strategy, the practitioner-researcher ensured students could work autonomously. They were tested orally and in groups until it was confirmed that they had mastered memorizing the mnemonics, their meanings, and their translation. Most students were able to revise their self-regulation plans independently. The practitioner-researcher provided additional support to weaker learners and enhanced this stage by collaborative practice activities (flashcards, role play, debate, quizzes, markers, and scratch paper). The concept of transfer to other settings was reviewed and discussed collaboratively. To boost instruction, plans for maintenance and generalization were practiced in groups of two. A post-test was administered to both groups following the 15 weeks of intervention (see above).

\section{Results}

\subsection{Data Analysis}

The scope of the statistical analysis was to examine the differences of students' performance between the conditions (Experimental and Control) as well as the time (Pre-test and Post-test) factor and if these were statistically significant. For the statistical analysis of this study a 2 (conditions: Experimental, Control) x 2 (time: Pre, Post) repeated measures analysis of variance was exploited and subsequently three univariate analyses. These referred to the three argumentative English writing criteria (content, analytic, and quantitative criteria). A paired sample and independent $\mathrm{t}$-test was exploited to examine significant differences within and between effects respectively. The margin for accepting a difference as statistically significant was set to the $p$-value $<0.5$. If the assumption of sphericity (equality of variances of the differences between pairs of conditions) for the repeated measures analysis of variance was not met in the within-subjects' analyses (Mauchly test of sphericity) the F estimation was based on the Green-House Geisser correction (Field, 2009; Tabachnick \& Fidell, 2009). The sample consisted of 177 students ( $49.72 \%$ female and $50.28 \%$ male) of which $50.84 \%$ were fifth graders and the rest sixth.

\subsection{Preliminary Analysis}

The univariate and multivariate distributions were examined (Tabachnick \& Fidell, 2009) and their skewness and kurtosis values of the argumentative English writing criteria (content, analytic and quantitative criteria) were found acceptable. The Pillai's Trace was used because of its tolerance over test violations (Field, 2009; Tabachnick \& Fidell, 2009). In this data the assumption of the equality of covariance matrices was not fulfilled at multivariate (Box's M test) whereas it was met at the univariate level (Levene's test).

\subsection{Main Analysis}

Before the test, the argumentative English writing criteria (content, analytic and quantitative criteria) between the 
Experimental and the Control group of participants were examined. There was no significant difference between the two groups at Pre-Test and Post-Test (Pillai's Trace $=0.920, \mathrm{~F}_{1,175}=4.982, \mathrm{~ns}, \mathrm{n}_{\mathrm{p}}^{2}=0.080$ ). In order to examine the effect of time (at Pre-Test and Post-Test) and condition (Control and Experimental) a repeated measure multivariate analysis of variance was used. There was a statistically significant interaction of condition (2) $\mathrm{x}$ time (2) (Pillai's Trace $\mathrm{V}=0.710, \mathrm{~F}_{1,175}=429.339, \mathrm{p}<0.001, \mathrm{n}_{\mathrm{p}}^{2}=0.710$ ). Also, the results showed a significant effect of condition (Pillai's Trace $\mathrm{V}=0.302, \mathrm{~F}_{1,175}=68.916, \mathrm{p}<0.001, \mathrm{n}_{\mathrm{p}}^{2}=0.28$ ) and time (Pillai's Trace $\mathrm{V}=0.579$, $\left.\mathrm{F}_{1,175}=240.436, \mathrm{p}<0.001, \mathrm{n}_{\mathrm{p}}^{2}=0.579\right)$. In Table 1. below the means and standard deviations of the argumentative English writing criteria (content, analytic and quantitative criteria) are presented.

Table 1. Mean Values (M) and standard deviations (SD) of the argumentative English text evaluation factors

\begin{tabular}{lllll}
\hline & Control Group & & \multicolumn{2}{l}{ Experimental Group } \\
\cline { 2 - 5 } & Initial & Final & Initial & Final \\
& M (SD) & M (SD) & M (SD) & M (SD) \\
\hline Content & $2.64(1.98)$ & $3.90(1.95)$ & $3.48(2.18)$ & $9.66(3.78)$ \\
Analytic Criteria & $2.37(1.75)$ & $3.86(2.10)$ & $3.31(1.78)$ & $10.05(3.17)$ \\
Quantitative Criteria & $42.47(21.87)$ & $33.75(20.89)$ & $48.16(18.27)$ & $73.36(24.51)$ \\
\hline
\end{tabular}

A significant interaction condition $\mathrm{x}$ time of $\mathrm{F}_{1,175}=258.243, \mathrm{p}<0.001, \mathrm{n}_{\mathrm{p}}^{2}=0.57$ was shown after the subsequent analysis of variance on the content variable. The participants of the Experimental group showed a statistically significant improvement over time of 6.18 with $\mathrm{t}$-test $=20.78, \mathrm{p}<0.001$. The Control group showed a substantially lower improvement of 1.26 with t-test $=9.00, p<0.001$. In the post-test there was a statistically significant difference between the Experimental and the Control group of 5.76 with t-test $=-13.14, p<0.001$, while at Pre-Test and Post-Test there was a difference between the two groups of 0.84 with $\mathrm{t}$-test $=-2.69$.

The analytic criteria showed a significant condition $\mathrm{x}$ time $\mathrm{F}_{1,175}=388.797, \mathrm{p}<0.001, \mathrm{n}_{\mathrm{p}}^{2}=0.690$, interaction. In the Experimental group, significant improvements were found with a difference of 6.74 with (t-test $=26.59, \mathrm{p}<0.001$ ). On the other hand, the Control group also showed an increase, but with 1.49, it was definitely smaller (t-test=9.20, $\mathrm{p}<0.001)$. The statistically significant difference between the Experimental and the Control group at Post-Test was 6.19 (t-test=-12.98, $\mathrm{p}<0.001$ ) whereas at Pre-Test and Post-Test the difference was 0.94 ( $\mathrm{t}$-test=-3.77, $\mathrm{p}<0.001$ ).

A significant interaction condition $\mathrm{x}$ time of $\mathrm{F}_{1,175}=309.608, \mathrm{p}<0.001, \mathrm{n}_{\mathrm{p}}^{2}=0.64$ was revealed after the subsequent analysis of variance on the quantitative criteria. Although the Control group showed a significant decrease on the quantitative criteria with $\mathrm{t}$-test $=6.74$, the Experimental group showed a significant increase of 25.20 with $\mathrm{t}$-test $=17.78, \mathrm{p}<0.001$. Prior to the test the difference between the Control and the Experimental group was not significant while at Post-Test the difference was 39.61 with $\mathrm{t}$-test $=9.98, \mathrm{p}<0.001$.

\subsection{Differences Between Participants of Different Writing Quality (Below Average and Average) of the Argumentative English Writing Criteria}

An analysis of relatively well-performing students and of those with difficulties revealed a significant condition (2: Control - Experimental) x Writing Quality (2: Below Average - Average) interaction (Pillai's Trace V=0.212, $\left.\mathrm{F}_{6,170}=15.251, \mathrm{p}<.001, \eta_{\mathrm{p}}^{2}=0.21\right)$ on the argumentative English writing criteria. Moreover, significant Writing Quality (Pillai's Trace V=0.129, $\mathrm{F}_{1,175}=15.251, \mathrm{p}<.001, \eta_{\mathrm{p}}^{2}=0.17$ ) and condition (Pillai's Trace $\mathrm{V}=0.212$, $\mathrm{F}_{1,175}=24.739, \mathrm{p}<.001, \eta_{\mathrm{p}}^{2}=0.67$ ) effect was evident.

A repeated measures multivariate analysis for only the below average students was used. This was tested to show any difference in the argumentative English text regarding the writing variables of content, analytic criteria and quantitative with time (pre-post). The results showed significant condition (2) x time (2) effect (Pillai's Trace $\left.\mathrm{V}=0.283, \mathrm{~F}_{1,147}=371.814, \mathrm{p}<.001, \eta_{\mathrm{p}}^{2}=.717\right)$. Means and the standard deviations of the below average participants of the Control and the Experimental group at Pre-Test and Post-Test are shown below.

Table 2. Mean Values (M) and standard deviations (SD) of below average participants for the evaluation factors of the argumentative English text

\begin{tabular}{lllll}
\hline & Control Group & & \multicolumn{2}{l}{ Experimental Group } \\
\cline { 2 - 5 } & Initial & Final & Initial & Final \\
& $\mathrm{M}(\mathrm{SD})$ & $\mathrm{M}(\mathrm{SD})$ & $\mathrm{M}(\mathrm{SD})$ & $\mathrm{M}(\mathrm{SD})$ \\
\hline Content & $2.13(1.16)$ & $3.41(0.98)$ & $2.68(1.43)$ & $8.41(3.31)$ \\
Analytic Criteria & $1.96(1.18)$ & $3.33(1.09)$ & $2.51(0.98)$ & $9.03(2.86)$ \\
Quantitative Criteria & $39.00(19.76)$ & $29.97(16.95)$ & $47.71(14.35)$ & $65.37(19.54)$ \\
\hline
\end{tabular}


To begin with the analysis of content showed a significant effect of condition $x$ time $(\mathrm{F}=247.26, \mathrm{p}<.001$, $\left.\eta_{\mathrm{p}}^{2}=0.572\right)$, condition $\left(\mathrm{F}_{1,147}=115.777, \mathrm{p}<.001, \eta_{\mathrm{p}}^{2}=0.441\right)$ and time $\left(\mathrm{F}_{1,147}=487.347, \mathrm{p}<.001, \eta_{\mathrm{p}}^{2}=0.768\right)$ interaction. The Experimental group regarding the content showed a statistically significant improvement at Post-Test of 5.73 with t-test $=17.32$ and $p$-value $<0.001$. The Control group at Post-Test showed a statistically significant growth for the content of 1.28 with $\mathrm{t}$-test $=9.22$, p-value $<0.05$.

A significant effect of condition $x$ time $\left(F_{1,147}=303.754, p<.001, \eta_{p}^{2}=0.674\right)$, condition $\left(F_{1,147}=695.585, p<.001\right.$, $\left.\eta_{\mathrm{p}}^{2}=0.567\right)$ and time $\left(\mathrm{F}_{1,147}=713.448, \mathrm{p}<.001, \eta_{\mathrm{p}}^{2}=0.829\right)$ interaction was shown for the analytic criteria. The Experimental group demonstrated a statistically significant improvement at Post-Test of 6.52 with $\mathrm{t}$-test $=21.5$, $\mathrm{p}<0.001$. The Control at Post-Test showed improvement of 1.37 with $\mathrm{t}=10.28$ with $\mathrm{p}<0.05$.

The quantitative criteria analysis showed significant condition $x$ time $\left(F_{1,147}=269.316, p<0.001, \eta_{p}^{2}=0.647\right)$, condition $\left(\mathrm{F}_{1,147}=45.296, \mathrm{p}<.001, \eta_{\mathrm{p}}^{2}=0.236\right)$ and time $\left(\mathrm{F}_{1,147}=53.910, \mathrm{p}<0.001, \eta_{\mathrm{p}}^{2}=0.268\right)$ interaction. The students of the Experimental group showed a statistically significant improvement at Post-Test of 17.66 with $\mathrm{t}$-test $=15.80, \mathrm{p}<0.001$ whereas the Control group indicated a significant decrease at Post-Test of -9.03 with t-test $=-7.06, \mathrm{p}<0.05$.

In the same way, a repeated measures multivariate analysis was used in order to examine the writing performance of the average participants over time (at Pre-Test and post-test) in both conditions (Experimental and Control). For the argumentative English writing criteria there was a significant condition (2) x time (2) effect (Pillai's Trace $\mathrm{V}=0.344, \mathrm{~F}=47.643, \mathrm{p}<.001, \eta_{\mathrm{p}}^{2}=.717$ ) interaction. The descriptive statistics of the average students of the Control group and the Experimental group over time are presented in Table 3 below.

Table 3. Mean Values (M) and standard deviations (SD) of average participants for the evaluation factors of the argumentative English text

\begin{tabular}{lllll}
\hline & Control Group & & \multicolumn{2}{l}{ Experimental Group } \\
\cline { 2 - 5 } & Initial & Final & Initial & Final \\
& M (SD) & M (SD) & M (SD) & M (SD) \\
\hline Content & $6.72(1.77)$ & $7.78(2.55)$ & $6.11(2.21)$ & $13.78(1.77)$ \\
Analytic Criteria & $5.61(1.58)$ & $8.11(2.71)$ & $5.94(1.14)$ & $13.42(1.22)$ \\
Quantitative Criteria & $71.33(12.53)$ & $63.89(20.56)$ & $69.33(13.11)$ & $99.56(20.85)$ \\
\hline
\end{tabular}

A condition $x$ time $\left(F=49.583, p<0.001, \eta_{p}^{2}=0.665\right)$, condition $\left(F=14.777, p<0.05, \eta_{p}^{2}=0.372\right)$ and time $(F=86.306$, $\mathrm{p}<0.001, \eta_{\mathrm{p}}^{2}=0.775$ ) interaction was showed from the content analysis. The Experimental group of the average students showed a statistically significant improvement at Post-Test in the content of 7.67 with t-test $=14.02$, p-value $<0.001$ while the participants of the Control group showed a statistically insignificant increase at Post-Test of 1.06 with $\mathrm{t}$-test $=1.40$ and $\mathrm{p}$-value $=0.19>0.05$.

In the analytic criteria there was a significant condition $x$ time $\left(F=67.138, p<0.001, \eta_{p}^{2}=0.729\right)$, condition $\left(\mathrm{F}=24.278, \mathrm{p}<0.01, \eta_{\mathrm{p}}^{2}=0.493\right)$ and time $\left(\mathrm{F}=270.055, \mathrm{p}<0.001, \eta_{\mathrm{p}}^{2}=0.915\right)$ interaction. The average students of the Experimental group improved significantly at Post-Test with a difference of 7.48 with $t$-test $=26.55, p<0.001$ over time (prior-post) while the Control group showed an increase at Post-Test of 2.5 with t-test $=3.81 \mathrm{p}<0.05$.

The analysis of the quantitative criteria indicated a significant condition $x$ time $\left(F=32.278, p<0.001, \eta_{p}^{2}=0.564\right)$, condition $\left(\mathrm{F}=7.295, \mathrm{p}<0.05, \eta_{\mathrm{p}}^{2}=0.226\right)$ and time $\left(\mathrm{F}=11.803, \mathrm{p}<0.05, \eta_{\mathrm{p}}^{2}=0.321\right)$ interaction. The Experimental group had a statistically significant increase at Post-Test of 30.23 with $\mathrm{t}$-test $=8.95, \mathrm{p}<0.05$. On the other hand, the decrease of the Control group at Post-Test was statistically insignificant.

\section{Discussion}

The purpose of this study was to evaluate the effects of POW+TREE as a specific SRSD strategy on the argumentative texts of grade five and grade six EFL learners with and without writing difficulties. Findings of the study surpassed our initial expectations. That is, the specific intervention program applied showed such concrete effects that it could be effectively incorporated in EFL settings that aim to foster the process approach to writing.

The differences between the participants of the control and the experimental group in the initial measurements were not statistically significant. However, at post-test, the students that received explicit strategy instruction outperformed the participants of the control group by a great margin. This factor substantiates the positive impact of the specific intervention program applied. Specifically, the effect sizes for the condition $\mathrm{x}$ time interactions reached remarkably high levels for all four measures of success - content-related criteria $\left(\eta_{p}^{2}=.57\right)$, analytic criteria $\left(\eta_{\mathrm{p}}^{2}=.69\right)$, and quantitative criteria $\left(\eta_{\mathrm{p}}^{2}=.64\right)$. These extraordinarily large indices signify the positive impact 
of the intervention program applied.

It is noteworthy that the participants in the experimental group showed improvement in all assessed criteria i.e., content, analytic criteria, and quantitative criteria. In antithesis, the participants of the control group did not show significant improvement in all assessed criteria and even showed a statistical decrease in the quantitative criteria. Hence, following the implementation of the specific strategy, the participants of the experimental group, who were supported through explicit writing strategy instruction through the SRSD outperformed the participants of the control group in all criteria. This factor highlights the significant impact of the specific intervention program applied.

An important element of the study was the differentiation of participants (below average, and average participants) based on their writing quality. Below average participants of the experimental group showed a statistically significant improvement for all three variables (content, analytic and quantitative criteria) at post-test. However, below average participants of the control group showed inconsistent results for the three assessed criteria (content, analytic criteria, and quantitative criteria). Specifically, they showed a statistically significant improvement for content and analytic criteria however, a statistically significant decrease for the quantitative criteria. These results should be stressed as they were not evident for participants of the experimental group. It can be hypothesized thus, that below average participants of the control group showed improvement in content and analytic criteria but nonetheless substantially lower than those of the experimental group because of writing anxiety. A study by Cheng, Horwitz and Schallert (1999) has shown a relationship between anxiety and writing achievement. The study noted that students with second language writing anxiety may suffer from low self-confidence in writing, negative feelings about the writing process in general, and/or fear of negative evaluation.

The average participants of the experimental group showed a significant increase in all assessed criteria at post-test. On the other hand, the average students of the control group showed insignificant improvement in the content, a minor increase in analytic criteria, and an insignificant decrease in the quantitative criteria at post-test. It is worthy to stress that following the intervention program applied to all students (average, below average) of the experimental group regardless of writing ability revealed a highly significant improvement in all the factors examined. This clearly notes that the intervention program proved to be exceptionally advantageous to all students irrespective of writing ability. It appears that the specific intervention program can be applied to participants of various writing abilities.

This study supports previous studies (Berry \& Mason, 2012; Glaser \& Brunstein, 2007; Graham \& Perin, 2007; Mason et al., 2013), that have validated the positive effects of the TREE+SRSD instructional model on students' argumentative writing skills. In this study, explicit strategy instructed students developed the necessary skills to effectively self-monitor their progress through self-regulation strategies, develop strategic writing behavior (planning, drafting, revising, thinking about audience etc.) and writing awareness. The findings of this study corroborate precious studies by Graham, Harris, and Mason (2005) that have noted that SRSD instructed students outperformed students in the comparison condition in (length, quality and writing knowledge) in argumentative writing. The findings also confirm previous studies that have shown the positive effects of SRSD on struggling second grade students' writing performance in argumentative writing, and enhanced writing knowledge (Harris, Graham \& Mason, 2006). What's more, the findings of this study align with a previous study by Baghbadorani and Roohani (2014) who found that SRSD instructed University classes highly outperformed non-SRSD (i.e., a more product-oriented traditional method) instructed classes at two Universities. Furthermore, the results of this study corroborate with a study by Cuenca-Carlino, Gozur et al. (2018) who found that following the SRSD intervention students' abilities to write argumentative papers significantly improved. The findings of this study also corroborate with a previous study by Graham, Harris, and Mason (2005) who noted that SRSD instructed students outperformed students in the comparison condition (length, quality and writing knowledge) in argumentative writing. The findings also confirm a study by Harris, Graham and Mason (2006) who found positive effects of the SRSD on struggling second grade students' writing performance in argumentative writing and enhanced writing knowledge.

\subsection{Conclusion}

Essentially, the promising results of this study validate that the SRSD is a fruitful method of instruction for all students, but particularly so, for students who struggle with various aspects of the writing process during English Foreign Language writing acquisition. The specific writing intervention applied showed to effectively facilitate all participants to navigate the complex cognitive and mental processes that English foreign language writing entails and aided participants to improve their writing skills. Writing is a challenging act, but these challenges are significantly exacerbated when writing in a foreign language especially for students with writing difficulties. The 
importance of a good command in English writing cannot be overestimated and the need for it will only continue to grow. Young grade school English language learners are a vulnerable group of learners whose difficulties are often misinterpreted. It is hence imperative that these young learners are adequately supported to build strong English writing skills that will enable them to pursue their future goals in both a personal and occupational level. The findings of this study contribute to research supporting the efficiency of the process approach to writing and suggest that foreign language settings incorporate explicit writing strategy instruction to efficiently support young foreign language learners. The results of this study provide additional evidence supporting the effectiveness of the SRSD on students' writing achievement. What's more, it could be hypothesized that the improvements found in students' writing could also lead to reading improvements. Graham and Hebert (2011) in their meta-analysis of true and quasi-experiments validated the established notion that writing and reading are interlinked. That is, they found that writing instruction highly facilitates reading comprehension, reading fluency, and that increased writing practice improves reading comprehension. Finally, the SRSD is an instructional method that can be easily applied by teachers in a plethora of English writing settings to support students with writing instruction.

\subsection{Limitations and Suggestions for Future Research}

This study had several pedagogical limitations that are important to note in interpreting the results. First, the results of this study are limited by the nature of the specific population used. That is, grade five and six EFL learners from Chania, Crete, Greece. Fifth and sixth grade students were intentionally selected as our target population as students at this age start to become more mature writers and have had adequate writing exposure and experience in both their first language and foreign language. Hence, they are sophisticated enough to form beliefs about their own writing performance and writing beliefs. A second limitation deals with the absence of follow up data. The specific population of students was graduating from grade school and enrolling in high school, therefore, follow up data was not possible to collect. Additional studies with a different group of language learners and a different practitioner-researcher are required to generalize the results of this study. Nonetheless, the results showed that the SRSD proved to be an indispensable teaching method to support students with English foreign language argumentative writing as it provides the necessary strategies, structure, and self-regulatory processes to guide students throughout the writing process. Hence, it is recommended that future research that centers on interventions engaging explicit strategy instruction in foreign language writing settings also examine the possible effects of writing instruction on reading.

A third limitation is that literacy researchers, such as Bereiter and Scardamalia (1993), as well as Lave and Wenger (1991), who have done recent work in cognitive science, social cognition, and sociocultural approaches to language learning, agree that student engagement with texts in the disciplinary or classroom discourse community where learners use language for authentic purposes is more effective than overt instruction of decontextualized rules, as found in the grammar-translation method or other rote memorization approaches. Thus, it appears appropriate to embed cognitive strategies which have proven to work with L1 students and students who struggle with writing (like POW+TREE) into an L2 sociocultural theory by developing a meaningful task using the target language, by explicitly teaching the linguistic features of the genre of an argumentative essay, and by providing meaningful, interactive feedback on students' written work. Alongside the sociocultural turn in L2 education, the last 10 years have witnessed an interest in the use of the L1 to support L2 learning (Johnson, 2006).

\section{References}

Baghbadorani, E. A., \& Roohani, A. (2014). The impact of strategy-based instruction on L2 learners' argumentative writing. Procedia - Social and Behavioral Sciences, 98, 235-241. https://doi.org/10.1016/j.sbspro.2014.03.412

Ballinger, S., Lyster, R., Sterzuk, A., \& Genesee, F. (2017). Context-appropriate crosslinguistic pedagogy: Considering the role of language status in immersion education. Journal of Immersion and Content-Based Language Education, 5(1), 30-57. https://doi.org/10.1075/jicb.5.1.02bal

Bereiter, C., \& Scardamalia, M. (1987). The psychology of written composition. Hillsdale, N.J: Lawrence Erlbaum Associates.

Bereiter, C., \& Scardamalia, M. (1983). Does learning to write have to be so difficult? In A. Freedman, I. Pringle \& J. Yalden (Eds.), Learning to write: First language/second language. New York: Longman.

Berry, A. B., \& Mason, L. H. (2012). The effects of self-regulated strategy development on the writing of expository essays for adults with written expression difficulties: Preparing for the GED. Remedial and Special Education, 33(2), 124-136. https://doi.org/10.1177/0741932510375469

Benedek-Wood, E., Mason, L. H., Wood, P. H., Hoffman, K. E., \& McGuire, A. (2014). An experimental 
examination of quick writing in the middle school science classroom. Learning Disabilities: A Contemporary Journal, 12(1), 69-92.

Burbules, N. C., \& Torres, C. A. (Eds.). (2000). Globalization and education: Critical perspectives. Psychology Press.

Cheng, Y. S., Horwitz, E. K., \& Schallert, D. L. (1999). Language anxiety: Differentiating writing and speaking components. Language Learning, 49(3), 417-446. https://doi.org/10.1111/0023-8333.00095

Ciullo, S., Mason, L. H., \& Judd, L. (2021). Persuasive quick-writing about text: Intervention for students with learning disabilities. Behavior modification, 45(1), 122-146.

Cook, T. D., \& Campbell, D. T. (1979). The design and conduct of true experiments and quasi-experiments in field settings. In R. T. Mowday \& R. M. Steers (Eds.), Reproduced in part in Research in Organizations: Issues and Controversies Goodyear Publishing Company.

Cooper, C. R. (1977). Holistic Evaluation of Writing. Evaluating Writing: Describing, Measuring, Judging. Retrieved from https://eric.ed.gov/?id=ED143020

Cuenca-Carlino, Y., Gozur, M., Jozwik, S., \& Krissinger, E. (2018). The impact of self-regulated strategy development on the writing performance of English learners. Reading \& Writing Quarterly, 34(3), 248-262. https://doi.org/10.1080/10573569.2017.1407977

Cummins, J. (2008) BICS and CALP: Empirical and theoretical status of the distinction. In B. Street \& N. H. Hornberger (Eds.), Encyclopedia of Language and Education (2nd ed., vol. 2: Literacy, pp. 71-83). New York: Springer Science + Business Media LLC.

Datchuk, S. M., Kubina, R. M., \& Mason, L. H. (2015). Effects of sentence instruction and frequency building to a performance criterion on elementary-aged students with behavioral concerns and EBD. Exceptionality, 23(1), 34-53.

Dearden, J. (2015). English as a medium of instruction-a growing global phenomena: Final report. January.

Efremidou, E., Frouzaki, F., \& Reppa, E. Z. (2009). English 6th Grade Teacher's Book. Ministry of National Education and Religious Affairs. Pedagogical Institute. Athens: Patakis. Retrieved from http://ebooks.edu.gr/new/books-pdf.php?course=DSDIM-F101

Efremidou, E., Reppa, E. Z., \& Frouzaki, F. (2009). English 6th Grade Pupil's Book. Ministry of National Education and Religious Affairs. Pedagogical Institute. Athens: Patakis. Retrieved from http://ebooks.edu.gr/new/books-pdf.php?course=DSDIM-F101

Englert, C. S., \& Mariage, T. (2003). The sociocultural model in special education interventions: Apprenticing students in higher-order thinking. In Handbook of Learning Disabilities (pp. 450-467).

Field, A. (2009). Understanding statistics using SPSS.

Flower, L., \& Hayes, J. R. (1980). The cognition of discovery: Defining a rhetorical problem. College Composition and Communication, 31(1), 21-32. https://doi.org/10.2307/356630

Flower, L., \& Hayes, J. R. (1981). A cognitive process theory of writing. College Composition and Communication, 32(4), 365-387. https://doi.org/10.2307/356600

García, O., \& Li, W. (2014). Translanguaging: Language, bilingualism and education. London: Palgrave Macmillan. https://doi.org/10.1057/9781137385765

Gillespie, A., \& Graham, S. (2014). A meta-analysis of writing interventions for students with learning disabilities. Exceptional children, 80(4), 454-473.

Glaser, C., \& Brunstein, J. C. (2007). Improving fourth-grade students' composition skills: Effects of strategy instruction and self-regulation procedures. Journal of Educational Psychology, 99(2), 297-310. https://doi.org/10.1037/0022-0663.99.2.297

Graddol, D. (2006). English next (Vol. 62). London: British Council. Retrieved from https://englishagenda.britishcouncil.org/sites/default/files/attachments/books-english-next.pdf

Graham, S. (1999). The role of text production skills in writing development: A special issue-I. Learning Disability Quarterly, 22(2), 75-77. https://doi.org/10.2307/1511267

Graham, S., Collins, A. A., \& Rigby-Wills, H. (2017). Writing characteristics of students with learning disabilities and typically achieving peers: A meta-analysis. Exceptional Children, 83(2), 199-218. 
https://doi.org/10.1177/0014402916664070

Graham, S., \& Harris, K. (2014). Conducting high quality writing intervention research: Twelve recommendations. Journal of Writing Research, 6(2), 89-123. https://doi.org/10.17239/jowr-2014.06.02.1

Graham, S., \& Harris, K. R. (2000). The role of self-regulation and transcription skills in writing and writing development. Educational Psychologist, 35(1), 3-12. https://doi.org/10.1207/S15326985EP3501_2

Graham, S., Harris, K. R., MacArthur, C., \& Santangelo, T. (2018). Self-regulation and writing (2nd ed., pp. 138-152). Routledge. https://doi.org/10.4324/9781315697048-9

Graham, S., Harris, K. R., \& Mason, L. (2005). Improving the writing performance, knowledge, and self-efficacy of struggling young writers: The effects of self-regulated strategy development. Contemporary Educational Psychology, 30(2), 207-241. https://doi.org/10.1016/j.cedpsych.2004.08.001

Graham, S., Harris, K. R., \& McKeown, D. (2013). The writing of students with LD and a meta-analysis of SRSD writing intervention studies: Redux. Handbook of Learning Disabilities, 2, 405-438.

Graham, S., \& Hebert, M. (2011). Writing to read: A meta-analysis of the impact of writing and writing instruction on reading. Harvard Educational Review, 81(4), 710-744. https://doi.org/10.17763/haer.81.4.t2k0m13756113566

Graham, S., \& Perin, D. (2007). A meta-analysis of writing instruction for adolescent students. Journal of Educational Psychology, 99(3), 445-476. https://doi.org/10.1037/0022-0663.99.3.445

Hacker, D. J., Dunlosky, J., Graesser, A. C., \& Taylor \& Francis eBooks A-Z. (2009). Handbook of metacognition in education. New York: Routledge. https://doi.org/10.4324/9780203876428

Harris, K. R., \& Graham, S. (1996). Making the writing process work: Strategies for composition and self-regulation (2nd ed.). Cambridge, Mass: Brookline Books.

Harris, K. R., \& Graham, S. (1999). Programmatic intervention research: Illustrations from the evolution of self-regulated strategy development. Learning Disability Quarterly, 22(4), 251-262. https://doi.org/10.2307/1511259

Harris, K. R., Graham, S., \& Mason, L. H. (2003). Self-regulated strategy development in the classroom: Part of a balanced approach to writing instruction for students with disabilities. Denver: Love Publishing Co.

Harris, K. R., Graham, S., \& Mason, L. H. (2006). Improving the Writing, Knowledge, and Motivation of Struggling Young Writers: Effects of Self-Regulated Strategy Development with and without Peer Support. American Educational Research Journal, 43(2), 295-340. https://doi.org/10.3102/00028312043002295

Harris, K. R., Graham, S., Mason, L., \& Friedlander, B. (2008). Powerful writing strategies for all students. Baltimore, MD: Paul H. Brookes Pub. Co.

Harris, K. R., Graham, S., Mason, L. H., \& Saddler, B. (2002). Developing self-regulated writers. Theory into Practice, 41(2), 110-115. https://doi.org/10.1207/s15430421tip4102_7

Hoover, T. M., Kubina, R. M., \& Mason, L. H. (2012). Effects of self-regulated strategy development for POW+ TREE on high school students with learning disabilities. Exceptionality, 20(1), 20-38.

Johnson, K. (2006). The Sociocultural Turn and Its Challenges for Second Language Teacher Education. TESOL Quarterly, 40(1), 235-257. https://doi.org/10.2307/40264518

Kellogg, R. T. (1996). A model of working memory in writing. In the science of writing: Theories, methods, individual differences and applications Mahwah, NJ: Lawrence Erlbaum Associates.

Kellogg, R. T., \& Raulerson, B. A. (2007). Improving the writing skills of college students. Psychonomic Bulletin \& Review, 14(2), 237-242. https://doi.org/10.3758/BF03194058

Klingner, J., Boelé, A., Linan - Thompson, S., \& Rodriguez, D. (2014). Essential Components of Special Education for English Language Learners with Learning Disabilities: Position Statement of the Division for Learning Disabilities of the Council for Exceptional Children. Learning Disabilities Research \& Practice, 29(3), 93-96. https://doi.org/10.1111/ldrp.12040

Kolovou, E. K., \& Kraniotou, A. (2009a). English 5th Grade Teacher's Book. Ministry of National Education and Religious Affairs. Pedagogical Institute. Athens: Patakis. Retrieved from http://ebooks.edu.gr/new/books-pdf.php?course=DSDIM-F101

Kolovou, E. K., \& Kraniotou, A. (2009b). English 5th Grade Pupil's Book. Ministry of National Education and 
Religious Affairs. Pedagogical Institute. Athens: Patakis. Retrieved from http://ebooks.edu.gr/new/books-pdf.php?course=DSDIM-F101

Kroll, B. (2003). Exploring the dynamics of second language writing. Cambridge; New York: Cambridge University Press. https://doi.org/10.1017/CBO9781139524810

Lave, J., \& Wenger, E. (1991). Situated learning: Legitimate peripheral participation. New York, NY: Cambridge University Press. https://doi.org/10.1017/CBO9780511815355

Manchón, R. M., \& Matsuda, P. K. (2016). Handbook of second and foreign language writing. Boston, MA: De Gruyter. https://doi.org/10.1515/9781614511335

Martinez Agudo, J. D. (2014). English as a foreign language teacher education: Current perspectives and challenges. Amsterdam, Netherlands: Rodopi. https://doi.org/10.1163/9789401210485

Mason, L. H., Kubina, R. M., Kostewicz, D. E., Cramer, A. M., \& Datchuk, S. (2013). Improving quick writing performance of middle-school struggling learners. Contemporary Educational Psychology, 38(3), 236-246. https://doi.org/10.1016/j.cedpsych.2013.04.002

Melitz, J. (2018). English as a lingua franca: Facts, benefits and costs. The World Economy, 41(7), 1750-1774. https://doi.org/10.1111/twec.12643

Miller, K. M., \& Little, M. E. (2018). Examining the effects of SRSD in combination with video self-modeling on writing by third grade students with learning disabilities. Exceptionality, 26(2), 81-105.

Rogers, L. A., \& Graham, S. (2008). A meta-analysis of single subject design writing intervention research. Journal of Educational Psychology, 100(4), 879.

Rogers, M., Hodge, J., \& Counts, J. (2020). Self-Regulated Strategy Development in reading, writing, and mathematics for students with specific learning disabilities. Teaching Exceptional Children, 53(2), 104-112. https://doi.org/10.1177/0040059920946780

Rouse, A. G., \& Sandoval, A. (2018). Writing Interventions for Students with Learning Disabilities: Characteristics of Recent Research. Learning Disabilities: A Multidisciplinary Journal, 23(2), 1-17.

Ruan, Z. (2005). A metacognitive perspective on the growth of self-regulated EFL student writers. Reading Working Papers in Linguistics, 8, 175-202.

Samway, K. (2006). When English language learners write. Portsmouth, US: Heinemann

Santangelo, T., Harris, K. R., \& Graham, S. (2008). Using self-regulated strategy development to support students who have "Trubol giting thangs into werds". Remedial and Special Education, 29(2), 78-89. https://doi.org/10.1177/0741932507311636

Shora, N., \& Hott, B. (2016). Write on: Improving persuasive writing using the POW+ TREE strategy. Beyond Behavior, 25(2), 14-20.

Tabachnick, B. G., \& Fidell, L. S. (2009). Using multivariate statistics (7th ed.). Pearson.

Thyer, B. A. (2012). Quasi-experimental research designs. Oxford University Press. https://doi.org/10.1093/acprof:oso/9780195387384.001.0001

Tsiriotakis, I. K. (2013). Writing difficulties and feelings of anxiety during the acquisition of English as a foreign language. Retrieved from https://pqdtopen.proquest.com/pubnum/10857326.html

Weigle, S. C. (2002). Assessing writing. Cambridge: Cambridge University Press. https://doi.org/10.1017/CBO9780511732997

Wong, B. (1998). Reflections on current attainments and future directions in writing intervention research in learning disabilities. Advances in Learning and Behavioral Disabilities, 12, 127-150.

\section{Copyrights}

Copyright for this article is retained by the author, with first publication rights granted to the journal.

This is an open-access article distributed under the terms and conditions of the Creative Commons Attribution license (http://creativecommons.org/licenses/by/4.0/). 